\title{
Sofrimento no trabalho: significado para o auxiliar de enfermagem com dois vínculos empregatícios
}

\author{
Suffering in nursing: assistant's work with two jobs
}

Andreza Daher Delfino Sentone' ${ }^{1}$; Aurora Aparecida Fernandes Gonçalves²

\section{Resumo}

O objetivo principal deste trabalho foi apreender o significado do sofrimento no trabalho para auxiliares de Enfermagem com dois vínculos empregatícios. Trata-se de uma pesquisa na abordagem qualitativa, realizada a partir da entrevista com dois auxiliares de enfermagem que representavam o perfil traçado entre profissionais com dois vínculos empregatícios desta categoria. O referencial teórico adotado para a análise do discurso dos entrevistados foi o sofrimento psíquico atrelado à organização do trabalho com o enfoque de Cristopher Dejours. Como resultado observou-se que estes trabalhadores apresentaram diferentes maneiras de reagir ao sofrimento no trabalho.

Palavras-chave: Sofrimento no trabalho, trabalhador de enfermagem.

\begin{abstract}
The main objective of this paper was to point out some factors that can determine the suffering or satisfaction at work, among nursing assistants with two jobs. This research was carried out using the qualitative approach, based on an interview with two nursing assistants who represented the chosen profile among professionals with two jobs, in this category of employees. The theoretical reference used for the analysis of the interviewees' speech was the physical suffering related to the organization of work, using Christopher Dejours' ideas. As a result, it was observed that these workers presented different ways of reacting to the suffering at work.
\end{abstract}

Key-words: Suffering at work; nursing worker.

\section{Introdução}

A discussão de problemas ligados ao trabalho executado por funcionários, auxiliares de enfermagem, suas conseqüências para a saúde bem como para a qualidade e produtividade dos serviços prestados, tem importância estratégica para as empresas de serviços.
Em serviços de saúde, principalmente em hospitais, o sofrimento psíquico é uma questão de fundamental importância, uma vez que o profissional de saúde lida constantemente com a dor e o sofrimento do outro, e no limite, sua morte, o que lhe traz constante desafios. Além disso, podem existir situações em que a organização e o conteúdo do trabalho não lhe são favoráveis, o que aumenta o risco de agravar a sua saúde.

\footnotetext{
1 Enfermeira, Chefe da Divisão Materno-Infantil do Hospital Universitário Regional do Norte do Paraná e Docente de Enfermagem da Universidade Norte do Paraná. Condomínio Residencial Vale. e-mail: andrezadaher@ sercomtel.com.br

2 Docente do Departamento de Psicologia e Psicanálise do Centro de Ciências Biológicas da Universidade Estadual de Londrina.
} 
Este cenário se agrava a partir do momento em que o trabalhador possui dois vínculos empregatícios em diferentes instituições hospitalares. Assim o objetivo deste estudo foi apreender o significado do sofrimento no trabalho para auxiliares de Enfermagem com dois vínculos empregatícios.

\section{Metodologia}

O presente estudo trata-se de uma pesquisa descritiva com enfoque qualitativo que teve como ponto de partida, o levantamento dos dados compilados em quatorze entrevistas semi-estruturadas, realizadas com auxiliares de enfermagem com dupla jornada de trabalho, há pelo menos dois anos, e que atuavam numa unidade de internação do Hospital Universitário Regional do Norte do Paraná (HURNP). Este levantamento foi realizado em parceria com o Serviço Social do Núcleo de Bem Estar da Comunidade (NUBEC-HU).

De posse desses dados, traçamos um perfil da amostra, a qual teve como critérios a seleção de trabalhadores com uma situação sócio - econômica e familiar menos favorável à atuação profissional em dupla jornada de trabalho, seguindo levantamento realizado pelo NUBEC/ HU. Assim delimitamos para esta pesquisa a participação de dois profissionais, que ao serem convidados e informados sobre o objetivo desta, concordaram fazer parte do estudo.

Procedemos então a realização das entrevistas realizadas no HURNP, na cidade de Londrina, no período de agosto a novembro de 1999. A entrevista constava de uma questão aberta sobre o significado do trabalho para o participante tendo uma duração média de 50 minutos. A análise e interpretação dos dados foram realizadas segundo referencial da análise de discurso (MINAYO, 1994), a luz dos conhecimentos da escola de Christophe Dejours (DEJOURS; ABDOUCHELI; JAYET, 1994a).

\section{Discussão e Análise dos Dados}

Enfermagem é uma ciência humana, de pessoas e experiências com campo do conhecimento, fundamentações e práticas de cuidar dos seres humanos que abrangem do estado de saúde aos estados de doença mediada por transações pessoais, científicas, estéticas, éticas e políticas (LIMA, 1994, p.32).

A partir desta definição é possível evidenciar a complexidade das atribuições e tarefas executadas pela equipe de enfermagem.

Para realizar uma intervenção de enfermagem, sinônimo de interação humana, além da percepção dessas tensões permanentes é preciso que os atos de cuidar sejam articulados com princípios de conservação de energia e integridade pessoal, social, política e estrutural.

$\mathrm{O}$ entendimento da experiência de enfermagem transcende a abordagem da ciência, cuja marca é a distância. Esta experiência só pode ser compreendida com um toque de sensibilidade da imaginação criativa.

\section{Fatores de Sofrimento Psíquico no Trabalho}

Apresentaremos a seguir a análise da fala dos trabalhadores. Partimos primeiramente da premissa no enfoque Dejouriano (em destaque no quadro), em seguida citamos a fala do participante a síntese da análise, procurando levantar alguns fatores que determinam a causa de sofrimento ou prazer no trabalho.

\section{Entrevista 1}

Os auxiliares de enfermagem que estão sujeitos ao trabalho noturno, devido aos ritmos biológicos não respeitados, podem sofrer de "patologia do trabalhador noturno"

“... também fico muito tempo acordado. Acho que tudo isto está me deixando estressado, hipertenso, não consigo desligar e dormir". 
A incidência desta patologia está sujeita a muitas particularidades às quais devem estar alerta, tais como:

1) transcurso de certo tempo antes que as consequiências, algumas delas duradouras, manifestem-se, o que acentua a importância de se adotar nos estudos todas as precauções metodológicas necessárias;

2) existência de efeitos indiretos como os da insuficiência e dos transtornos nervosos ou digestivos (efeito indireto);

3) grande diversidade de reações de cada indivíduo segundo sua situação familiar, econômica e social, configurando uma tipologia em turnos (CARPENTER; CAZAMIAN apud SILVA, 1992).

\section{A organização do trabalho da enfermagem está centralizada no cumprimento das atribui- ções diárias, como fazer em detrimento ao porque fazer.}

“... Ter dois empregos não é mole, pois começo e termino tudo num e começo e termino tudo no outro tem que passar o plantão com tudo certinho parece que a gente não vê o tempo passar, é uma loucura."

O desgaste no trabalho do auxiliar de enfermagem é condicionado pelas situações de trabalho vigentes nos hospitais, cabendo salientar o ritmo e a carga de trabalho, o grau de autoritarismo das chefias, as fracas probabilidades de carreira e ascensão profissional, a inexistência de formas de participação (BELLATO; PASTI; TAKEDA, 1997).

Ao analisarmos os elementos presentes na organização do trabalho que os auxiliares de enfermagem realizam, percebemos elementos fortemente implicados na gênese do sofrimento do trabalhador, principalmente quando se observa uma forma de organização autocrática e autoritária, como podemos notar na fala do auxiliar de enfermagem.
Estas características geram bloqueios da relação conflitual do aparelho psíquico com a tarefa não oferecendo saída apropriada à energia punsional. Esta, ao não encontrar descarga no desenvolvimento do trabalho, acumula-se dando origem a um sentimento de desprazer, fadiga e tensão, demarcando, no dizer de Dejours (1994) o começo do domínio do sofrimento e da luta contra o sofrimento. Logo a existência de bloqueio na relação homem-organização do trabalho na área de enfermagem, apesar da máxima utilização das faculdades intelectuais, psicoafetivas, de aprendizagem e de adaptação ao buscarem diária e continuamente soluções para as demandas assistenciais que se apresentam dadas as dificuldades de realizarem diuturnamente as tarefas que lhe são destinadas (LUNARDI ; MAZZILI, 1996).

Sabemos que a profissão de enfermagem tem suas características bem definidas, delineadas pela habilidade e pela competência profissional, porém isto não impede que nas condições reais de trabalho, seja extremamente difícil a realização das tarefas.

O comportamento produtivo de um auxiliar de enfermagem pode estar motivado pelo salário ou prêmios, porém esse preço é pago pela troca da repressão do desejo e enclipsamento do sujeito (DEJOURS apud SEIJI, 1996).

"Trabalhar em dois empregos tem suas vantagens, agora eu me preocupo menos com a dificuldade em pagar as contas e sou mais reconhecido e valorizado pelos meus colegas de trabalho".

Levantamos nesta hipótese o eclipsamento do sujeito e, fizemos essa dedução através da significação que o sujeito analisado faz em relação aos pontos positivos de seu trabalho, ao estabelecimento e valorização do seu trabalho, ao reconhecimento e valorização dos seus pares. 
"Penso que a minha vida poderia ser melhor se eu tivesse mais tempo para o lazer e para estar com a minha família. Agora, o meu tempo é bem restrito e o que tenho fico com eles".

A lógica da produção de mercadorias atuando sobre o tempo livre do trabalhador, toma-lhe um espaço que poderia ser usado sobre si mesmo, reduzindo e/ou homogeneizando suas necessidades com reflexos profundos em sua personalidade, em suas relações com os outros e como mundo (LUNARDI, 1997).

Para o trabalhador quase inexiste momento de lazer e o prazer é poder estar menos preocupado com as suas finanças e ser mais reconhecido pelos seus colegas de trabalho. Enquanto ele é o responsável pela subsistência da família, se torna um escravo do mundo de consumo, dominado pela retórica "ideológica dominante" do sistema capitalista, que imprime no trabalhador a idéia de que o homem digno é aquele que trabalha muito.

\section{Para lidar com o sofrimento do outro o auxi- liar de enfermagem aprende a desenvolver estratégias defensivas, porém, às vezes, não consegue e sofre junto com o paciente.}

"No começo, a cada plantão que acabava eu ficava pensando nos pacientes e em seu sofrimento e isso me deixava triste e deprimido. Agora já me acostumei e não sofro tanto. É lógico, quando o paciente fica muito tempo internado, a gente pega amor e daí é mais difícil".

As estratégias defensivas são definidas como um mecanismo pelo qual o trabalhador busca modificar sua percepção da realidade que o faz sofrer.

Por meio da observação participante, percebemos que esta defensiva é coletiva, pois é entre os profissionais auxiliares de enfermagem, uma vez que eles convivem na presença de semelhantes condições externas e em um consenso de um grupo específico de trabalhadores.
Acreditamos que, por meio dessa estratégia coletiva os auxiliares de enfermagem conseguem uma estabilidade maior na luta contra o sofrimento, que em outras situações seriam incapazes de garantí-los apenas com suas defesas individuais.

\section{Entrevista 2}

O auxiliar de enfermagem que, apesar de trabalhar muito (em dupla jornada de trabalho), quando numa organização de trabalho que permita a liberação da descarga psíquica, o trabalho se torna prazeroso.

"Sabe eu gosto muito daqui e de lá. Aqui e lá a gente se dá bem com os colegas, faz festinhas e trabalha muito, muito..."

“... e o meu mais velho quando chega nos finais de semana me pergunta se eu tenho mesmo que ir trabalhar, fazer plantão. Eu explico para ele, você vão quer ganhar aquele carrinho? Então a mamãe tem que ir trabalhar..."

DEJOURS, ABDOUCHELI e JAYET (1994a, p.24), "o bem estar, em matéria de carga psíquica, não advém só da ausência de funcionamento, mas pelo contrário, de um livre funcionamento, articulado dialeticamente com o conteúdo da tarefa, expresso, por sua vez, na própria tarefa e revigorado por ela /.../ O prazer do trabalhador resulta da descarga de energia psíquica do trabalho /.../ se um permite a diminuição da carga psíquica, ele é equilibrante. O trabalho não é sempre patogênico. Ao contrário, tem poder estruturante em face tanto da saúde mental quanto a saúde física, logo, ao ser fonte de prazer, o trabalho é mediador da saúde".

O lidar com a doença e a morte suscita o surgimento de estratégias defensivas contra a ansiedade gerada pelo próprio trabalho, que pode ser atenuada ou exacerbada pelas relações de trabalho. 
"Aqui no hospital A é mais puxado, pois tem sempre muitas crianças doentes, e às vezes não é fácil você ver elas sofrendo, você cuida, cuida, cuida e às vezes no outro plantão você chega e a criança foi a óbito. Isto me deixa muito triste, eu e minhas colegas. Mas pelo menos a gente cuidou bem dela".

Segundo MENZIES apud PITTA (1990), as principais estratégias defensivas dos trabalhadores hospitalares são:

a) argumentação da relação técnico/paciente - se a relação for muito íntima, o profissional se tornará mais passível de angústia. Assim, o parcelamento da tarefa resulta em redução de tempo de contato com os pacientes;

b) despersonalização e negação da importância do indivíduo (todo paciente é igual), que se traduzem no uso de uniformes;

c) distanciamento e negação de sentimentos através do controle dos mesmos;

d) eliminação de decisões por meio de ritual de desempenho de tarefas, buscando rotinas e padronizações;

e) redução do peso da responsabilidade de em função do parcelamento, fragmentação e supervisão de tarefas.

Percebemos também nessa fala do trabalhador emergir o conceito de estratégia de defesa coletiva, que luta contra a doença mental e o alívio do sofrimento.

Apesar da natureza da atividade de enfermagem ser desgastante, por ser exercida em situações críticas pelas quais passa o ser humano, paradoxalmente, quando possível de ser realizada, na dependência dos resultados obtidos e por atender às necessidades de os trabalhadores de enfermagem se sentirem úteis e quererem ajudar, esta natureza é prazerosa.

São privações, as necessidades não supridas, as frustrações levam o trabalhador de enfermagem a tentar realizar uma compensação pelas frustrações lançando mão da ressonância simbólica e da sublimação.
"Eu dormia em cama que não tinha colchão, só aqueles paus, com uma coberta em cima deles. Às vezes até no chão".

“... queria arrumar coisa melhor /.../ não sobrava um dinheirinho para eu comprar roupa para mim, só era o leite do meu filho”.

“... tenho comigo que nem eu nem meus filhos vão passar pelo que passei”.

"Quando chego em casa estou morta de cansada, mas brinco com as crianças e até leio estórias para elas. Eu não quero que elas cresçam sem o carinho da mãe, sei que é muito importante, por isso posso estar cansada, mas fico com eles".

“... hoje a minha mãe é velhinha e está com 78 anos, ela e os meus irmãos tem o maior orgulho de mim e eu também fico orgulhosa, porque eu sofri muito /.../ olho para minhas crianças e vejo que não passaram por isto, e enquanto eu tiver coragem elas não vão passar necessidades".

“... mas fazer o quê a gente tem que trabalhar, posso dizer que eles não tem luxo, mas também não passam fome e tem tudo que precisam para viver."

Percebemos nos depoimentos acima colocados a articulação entre o teatro psíquico e o teatro do trabalho. O teatro do trabalho funciona como dispositivo disparador, como ocasião desencadeante para o adulto reatualizar o cenário original de sofrimento. Assim o trabalho possibilita ao indivíduo prosseguir em seu questionamento interior e traçar seu caminho, sua história.

"Na realidade, a ressonância simbólica tenta manter o equilíbrio mental individual no momento da difícil confrontação entre o inconsciente, composto por emoções que permanecem difusas e o ambiente produtivo real”. A ressonância simbólica “... é vista como tentativa de compensação pelas frustrações vivenciadas. A sublimação aparece como única opção para lidar de maneira racional com a carga emocional gerada pelo sofrimento" (LUNARDI FILHO \& MAZZILLI, 1996, p.66). 


\section{Conclusão}

A partir do referencial teórico escolhido, DEJOURS (1994b), e da fala dos trabalhadores, auxiliares de enfermagem, percebemos que os trabalhadores de uma mesma categoria profissional, submetidos a uma dupla jornada de trabalho, apresentam comportamentos diferentes frente ao trabalho. Vale ressaltar, ainda, que DEJOURS coloca a organização do trabalho como um aspecto fundamental para o trabalhador obter sofrimento ou prazer no trabalho, ou seja, cada categoria profissional está submetida a um modelo específico de organização do trabalho, o qual pode conter elementos homogêneos ou contraditórios, facilitadores ou não da saúde mental do trabalhador.

Podemos considerar, então, que tanto o modelo organizacional do trabalho prescrito pela organização, como as relações subjetivas dos trabalhadores com o trabalho têm papel fundamental na determinação das vivências de prazer ou sofrimento, de produtividade ou não.

Assim, a luz dos conhecimentos expostos é pertinente concluir que apesar de pertencerem a uma mesma categoria profissional e exercem uma dupla jornada de trabalho, os trabalhadores entrevistados tiveram diferentes posturas frente ao trabalho, uma vez que a organização do trabalho e os processos psicológicos diferem de pessoa para pessoa. Logo verificamos, na primeira entrevista, que o trabalhador relata o seu sofrimento no trabalho, o qual é denominado patogênico pelas características aqui já comentadas. Já o trabalhador da segunda entrevista consegue transformar seu sofrimento em um sofrimento criativo desfrutando assim de um trabalho prazeroso.

Agregados a esta conclusão, entendemos que a natureza do trabalho da enfermagem, sua essência taylorista na organização dos processos de trabalho, seu contato contínuo com a dor e o sofrimento humano, são fatores desencadeantes do sofrimento no trabalho e não o fato de realizarem dupla jornada de trabalho.

\section{Referências}

BELLATO, R.; PASTI, M. J.; TAKEDA, E. Algumas reflexões sobre o método funcional no trabalho da enfermagem. Revista Latino-Americana de Enfermagem, Ribeirão Preto, v.5, n.1. p.75-81, jan. 1997.

DEJOURS, C.; ABDOUCHELI, E.; JAYET, C. A carga psíquica do trabalho. In: .Psicodinâmica do trabalho: contribuições da escola dejouriana à análise da relação prazer, sofrimento e trabalho. São Paulo: Atlas, 1994a.

DEJOURS, C.; ABDOUCHELI, E.; JAYET, C. Itinerário teórico em psicopatologia do trabalho. Psicodinâmica do trabalho: contribuições dejouriana à análise da relação prazer, sofrimento e trabalho. São Paulo: Atlas, 1994b.

LIMA, M. J. de. O que é Enfermagem. São Paulo: Brasiliense, 1994.

LUNARDI FILHO, W. D.; MAZZILLI, C. O processo de trabalho na área da enfermagem: uma abordagem psicanalítica. Revista de Administração, São Paulo, v.31, n.3, p.63-71, jul./set. 1996.

LUNARDI FILHO, W. D. Prazer e sofrimento no trabalho: contribuições à organização do processo de trabalho da enfermagem. Revista Brasileira de Enfermagem, São Paulo, v.50, n.1, p. 77-92, jan./mar. 1997.

MINAYO, M. C. S. (Org.) Pesquisa Social: Teoria, método e criatividade. 15.ed. Petrópolis: Vozes, 1994.

PITTA, A.M.F. Hospital: dor e morte como ofício.3.ed., São Paulo, Hucitec, 1999.

SEIJI, U. Temporalidade e subjetividade no trabalho informativo. 1996. Tese (Doutorado em Psicologia) Instituto de Psicologia da Universidade de São Paulo, São Paulo.

SILVA, E. S. A inter-relação trabalho-saúde mental: um estudo de caso. Revista de Administração de empresas, São Paulo, v.32, n 4, p.70-90, set./out. 1992. 